\title{
Members of the Month
}

\author{
Victor Asal \\ JUNE MEMBER OF THEMONTH \\ University of Albany
}

"The moment when you can help a student see the world in a different way that helps them understand, for example, discrimination and privilege in our world today, is an accomplishment that makes all the hard work worthwhile."

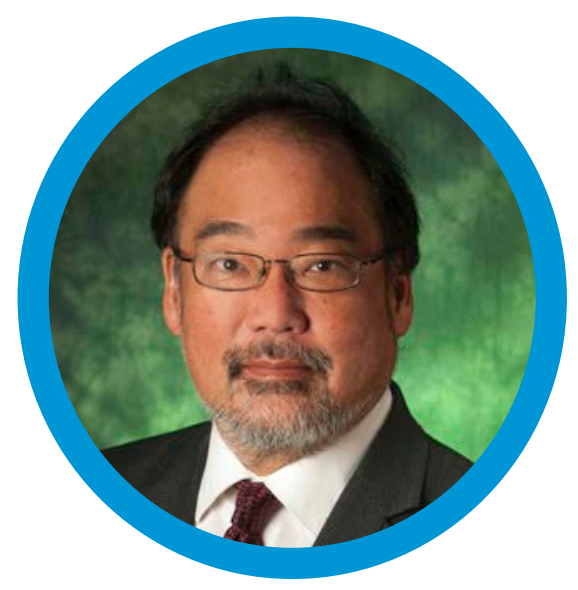

\section{JOHN ISHIYAMA \\ JULY MEMBER OF THE MONTH \\ University of North Texas}

"I have long believed that central to what we do is both teaching and scholarship/research. This is because I have long believed that if you teach and do not do research, then what is it you are teaching? And if you do research and not teach to share that knowledge, then what is the point of doing the research? So both are necessary parts of being a political scientist."

The APSA Member of the Month program recognizes one member each month. Nominations for the award (including self-nominations) may be submitted by members and nonmembers of APSA. To submit your nomination visit our member of the month page online: www.apsanet.org/motm. 